\title{
Effect of impulsive force on earthquake response of rocking structural systems
}

\author{
T. Azuhata ${ }^{1}$, T. Ishihara ${ }^{1} \&$ M. Midorikawa ${ }^{2}$ \\ ${ }^{I}$ National Institute for Land and Infrastructure Management, Japan \\ ${ }^{2}$ Hokkaido University, Japan
}

\begin{abstract}
To reduce seismic damage of steel building structures, a rocking structural system which employs the yielding mechanism of base plates has been suggested by the authors. When weak base plates yield due to column tension during a strong earthquake ground motion, the columns uplift and enable the building structure to rock. The performance of the suggested system for earthquake response reduction has previously been successfully demonstrated by the use of shaking table tests on a three story half scale braced frame. However, these tests also established that considerable vertical impulsive force occurs at the column bases when the uplifting columns touch down to their original position. The objective of this study is to investigate the influence of this impulsive force on earthquake response of real scale rocking structures. Earthquake response analyses are carried out on a steel model frame with yielding base plates. The frame has ten stories and one bay. The height and the width are $37.8 \mathrm{~m}$ and 7.5 $\mathrm{m}$, respectively. The viscous damping is assumed to be proportional to the initial stiffness. The critical damping ratio of $2.0 \%$ is introduced to the first mode. The analysis results showed that vertical response acceleration on the frame is largely and instantly amplified by the impact effect when the uplifting column touches down. However, the impulsive vertical force does not damage the column, because it damps very quickly under the assumption of stiffness-proportional viscous damping.

Keywords: rocking structural system, uplift, impulsive force, seismic damage reduction, yielding base plate, steel building structure.
\end{abstract}




\section{Introduction}

Past studies have pointed out that the effects of rocking accompanied with uplift motion may reduce the seismic damage to buildings subjected to strong earthquake ground motions [for example, 1-3]. Based on these studies, structural systems have been developed that permit rocking vibration and uplift motions under appropriate control during strong earthquake ground motions [4-10]. The past shaking table tests by the authors on a three story half scale braced frame verified that the rocking structural system, which employs the yielding mechanism of the base plates, can reduce earthquake responses of the frame [710]. However, these tests also showed that the considerable vertical impulsive force occurs at the column bases by the impact effect when the uplifting columns touch down to their original position. When applying the rocking structural systems to real buildings, we need to clear the influence of this impulsive vertical force. In this study, earthquake response analyses are carried out on a real scale model frame which is applied the rocking structural systems to and the influence of the impulsive vertical force on its earthquake responses is investigated.

Table 1: Section of structural members.

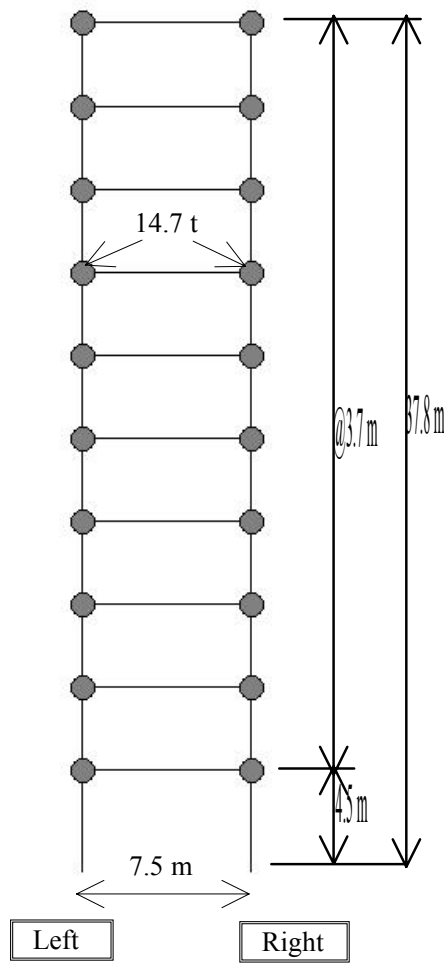

Figure 1: $\quad$ Model frame.

\begin{tabular}{|c|c|c|}
\hline & Floor & Section \\
\hline \multirow{2}{*}{ Column } & $8-10$ & $\square-500 \times 500 \times 19$ \\
\cline { 2 - 3 } & $1-7$ & $\square-500 \times 500 \times 25$ \\
\hline \multirow{2}{*}{ Beam } & $7-\mathrm{RF}$ & $\mathrm{H}-588 \times 300 \times 12 \times 20$ \\
\cline { 2 - 3 } & $2-6$ & $\mathrm{H}-700 \times 300 \times 13 \times 24$ \\
\hline
\end{tabular}

Table 2: $\quad$ Yield strength of steel.

\begin{tabular}{|l|l|}
\hline Beam under $2 \mathrm{~F}$ & $588\left(\mathrm{kN} / \mathrm{mm}^{2}\right)$ \\
\hline Other members & $294\left(\mathrm{kN} / \mathrm{mm}^{2}\right)$ \\
\hline
\end{tabular}

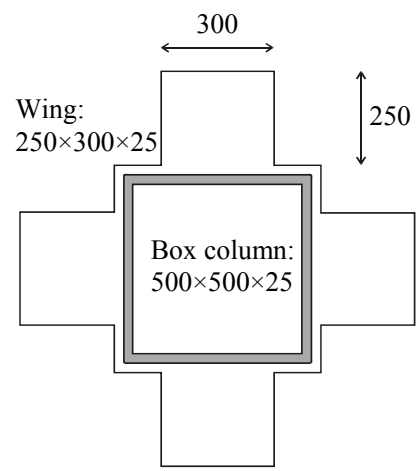

Figure 2: Plan of base plate with four thin wings. 


\section{Earthquake response of rocking structural system}

\subsection{Model frame and analytical procedure}

The model steel frame used in this study is shown in Fig. 1. The frame has ten stories and one bay. The height and the width are $37.8 \mathrm{~m}$ and $7.5 \mathrm{~m}$, respectively. The total weight is $2881.2 \mathrm{kN}$. To permit the frame uplift motion, the yielding base plate shown in Fig. 2 is attached at each column base on the first floor. The sections of the structural members are shown in Table 1. And yield strength of steel is shown in Table 2. Because the yielding base plate cannot fix the rotation of the column base, the beam under the second floor bends easily. Thus higher strength steel is used only for it. Fig. 3 shows the numerical model for the base part of the frame. To represent uplift motion, two types of springs are attached at each column base. The force-deformation relationships of the springs are shown in Fig. 3 (b)(c). As for base plates, the relationship shown in Fig. 3(b) is modeled based on the static test results $[11,12]$. The characteristic values of the base plate are shown in Table 3. The bending force-deformation relationship of edge parts of columns and beams is a normal-bilinear type. The M-N interaction is considered to evaluate response of columns.

Mode shapes and natural periods of the model frame are shown in Fig. 4. According to our past study, shaking table test results including the impact effect on the test frame that was permitted uplift motion can be represented by the FEM dynamic response analysis method assuming the viscous damping is proportional to the initial stiffness [10]. Thus the analysis procedure in this study is also based on the same assumption about the viscous damping. The critical damping ratios for three representative modes are shown in Table 4 . The ratio introduced to the first mode is $2 \%$. The predominant mode in vertical is the sixth mode with the natural period of $0.106 \mathrm{~s}$. The critical damping ratio for this mode is $29.48 \%$.

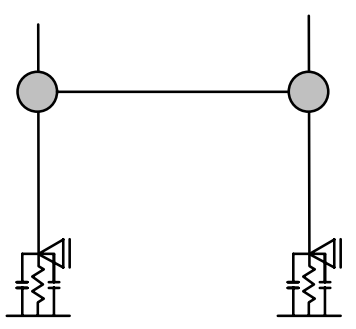

(a)

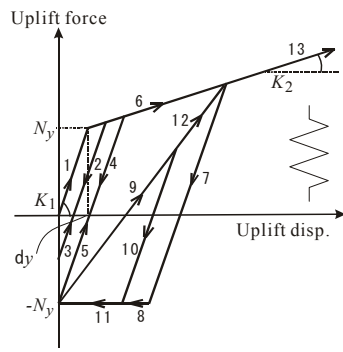

(b)

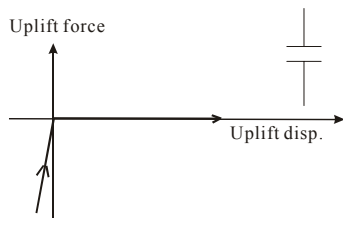

(c)

Figure 3: Numerical model for base part of frame. (a) The base of the rocking system, (b) base plate, (c) ground contact.

Table 3: $\quad$ Characteristic values of base plate.

\begin{tabular}{|c|c|c|c|}
\hline$Q y$ & $K 1$ & $\delta y$ & $K 2 / K 1$ \\
\hline $441(\mathrm{kN})$ & $146(\mathrm{kN} / \mathrm{mm})$ & $3.0(\mathrm{~mm})$ & 0.2 \\
\hline
\end{tabular}




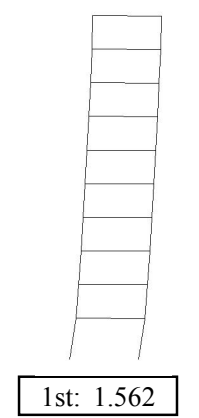

Figure 4:

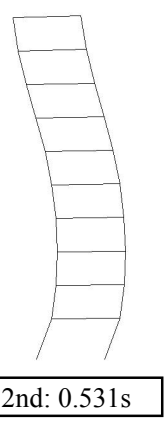

Mode shapes periods.

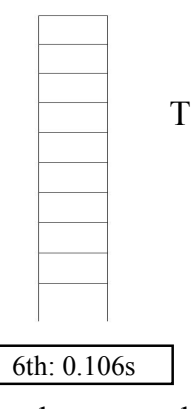

and natural
Table 4: $\quad$ Viscous damping ratios.

\begin{tabular}{|c|c|c|}
\hline & $\mathrm{T}(\mathrm{s})$ & $\mathrm{h}(\%)$ \\
\hline 1st & 1.562 & 2.00 \\
\hline 2nd & 0.531 & 5.88 \\
\hline 6th & 0.106 & 29.48 \\
\hline
\end{tabular}

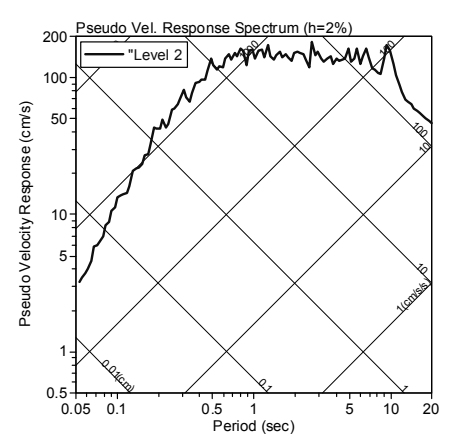

Figure 5: $\quad$ Tripartite response spectrum of input motion.

The input ground motion is an artificial ground motion (BCJ L2), which is used for structural design of high-rise buildings in Japan. The time duration is $120 \mathrm{~s}$ and the peak velocity is $0.5 \mathrm{~m} / \mathrm{s}$. The linear response spectrum for $1-\mathrm{DoF}$ systems with critical damping ratio $\mathrm{h}=2 \%$ is shown in Fig. 5. For calculating the earthquake responses, a step by step time history response analysis method is used. The time interval of numerical integration is $0.001 \mathrm{~s}$.

\subsection{Analysis results}

In Fig. 6, the maximum roof drift angle and base shear of the test frame with yielding base plates that permitted uplift motion (BPY model) are compared with those of the same frame whose bases are fixed (F model). Solid lines show the corresponding results of static pushover analyses for the both models. The Aidistribution, which is regulated by Japanese building seismic code, is used as the lateral force distribution for the static analyses. By permitting the frame uplift motion, the maximum base shear of the test frame can be reduced although the maximum roof drift angle is increased a little. Fig. 7 shows the damage aspect of the test frame with the bases fixed. Plastic hinges occur in some beams. In contrast, the analysis result for the test frame permitted uplift motion shows all structural members keep elastic except the yielding base plates. 


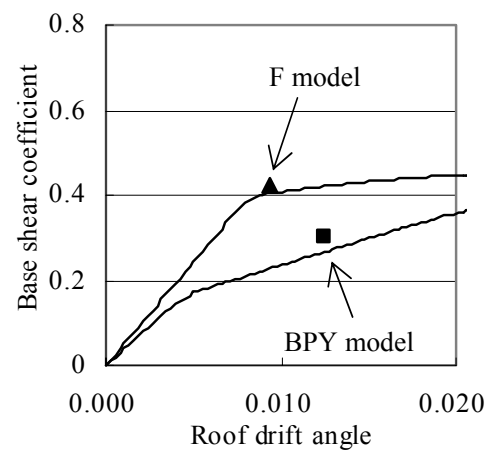

Figure 6: Roof drift angle and Figure 7: Damage aspect of F base shear coefficient.

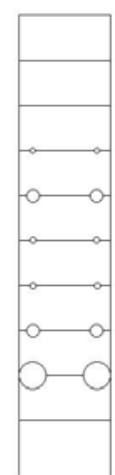

Radius of each white circle corresponds to amplified factor of accumulated plastic deformation. (Max: 5.12)

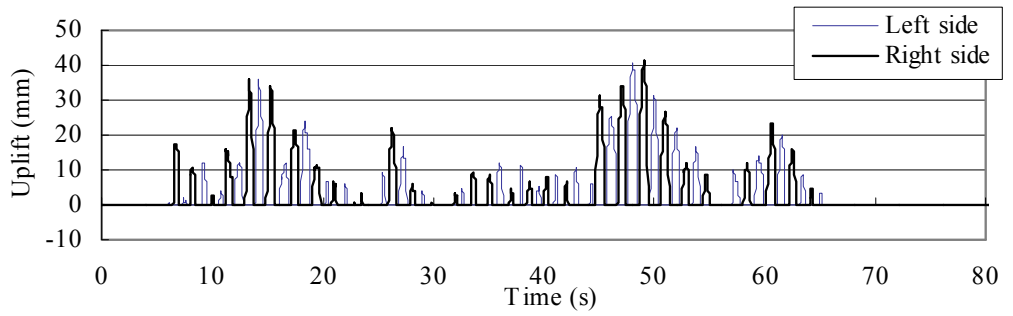

Figure 8 Time history of uplift displacement.

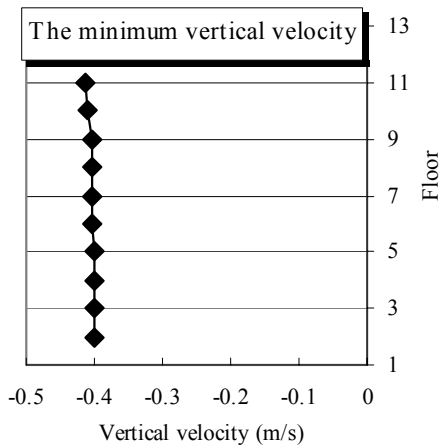

(a)

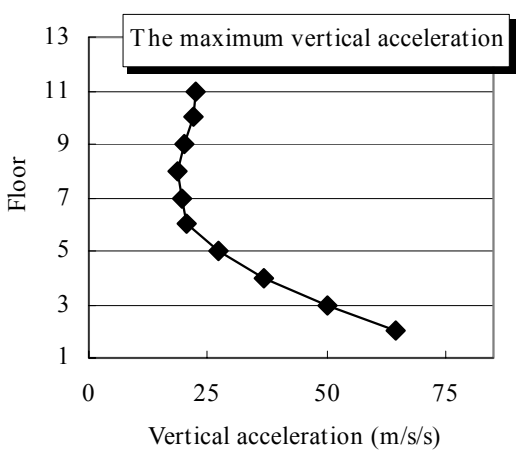

(b)

Figure 9: Peak vertical responses on each floor: (a) vertical velocity, (b) vertical acceleration.

Fig. 8 shows the time history of uplift displacements of the BPY model. The maximum value is about $40 \mathrm{~mm}$. This means the maximum rigid rotational angle 
of the frame is about 1/189. Fig. 9 shows the peak vertical velocity and acceleration on the each floor of the BPY model. These are observed in the right side. Fig 10 and Fig. 11 show time history of vertical forces at the column bases of the F model and the BPY model, respectively. Comparing Fig. 10 with Fig. 11, we can judge both compressive (minus) and tensile (plus) forces of the BPY model fall below those of the F model, although the peak vertical responses of the BPY model are largely amplified as shown in Fig. 9.

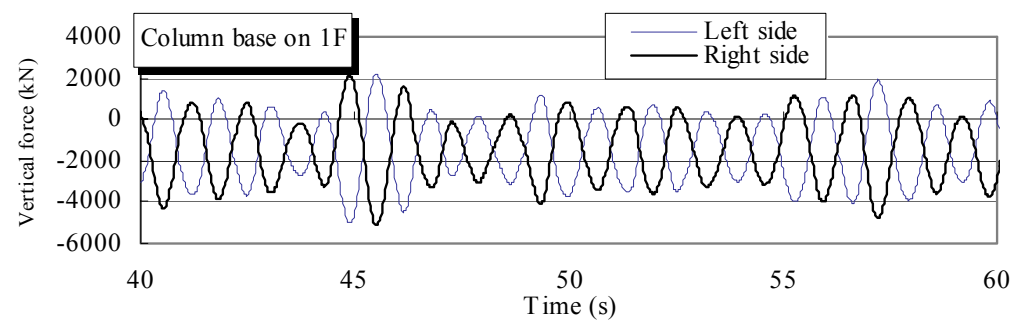

Figure 10: Time history of vertical force at base of F model.

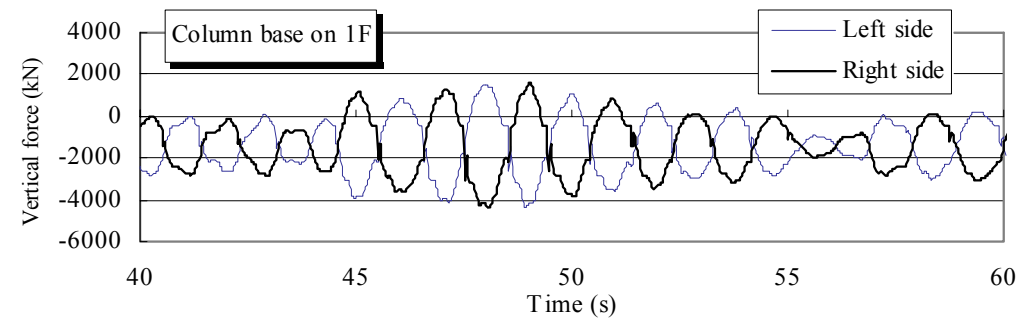

Figure 11: Time history of vertical force at base of BPY model.

\section{Discussion}

Impulsive vertical force $N_{I M P}$ at the column base of the rocking structural system with one bay is calculated by the following equation [9].

$$
N_{I M P}=\Delta N_{C O M}+\Delta N_{T E N}
$$

where: $\triangle N_{C O M}$ : Vertical force variation in the compressive side, $\Delta N_{T E N}$ : Vertical force variation in the tensile side.

For the fixed base model, the impulsive vertical force by eq. (1) is always zero that can be easily understood by seeing Fig. 10 .

The calculation results for the BPY model are shown in Fig. 12. The considerable impulsive forces are presented in this figure. By the way, the external vertical force ${ }_{R, L} F_{V i}$ by the vertical inertia effect in the left or right side of the each floor is calculated by the following equation. 


$$
{ }_{R, L} F_{V i}=\sum_{i=n}^{N} m_{n} \ddot{z}_{n}
$$

where, $m_{n}$ : mass of node, that is $14.7 \mathrm{t}$ in this study (see Fig. 1 ), $\ddot{z}_{n}$ : vertical response acceleration on the node in the right or left side of each floor.

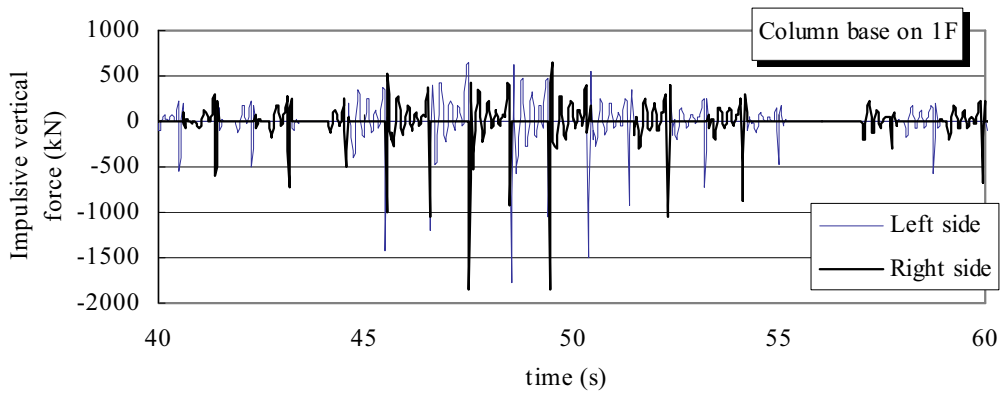

Figure 12: Time history of impulsive vertical force at base of BPY model.

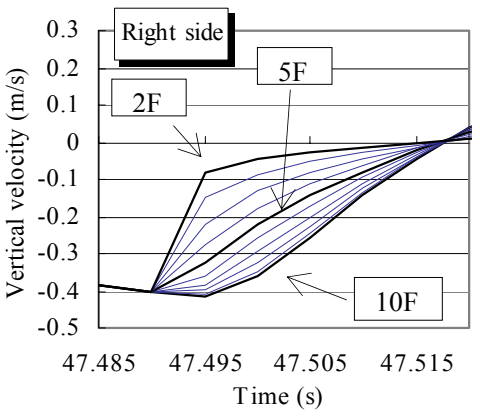

(a)

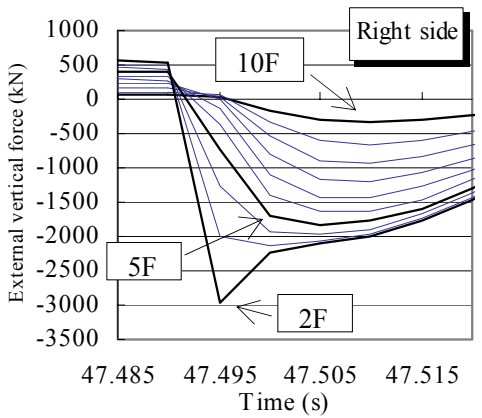

(c)

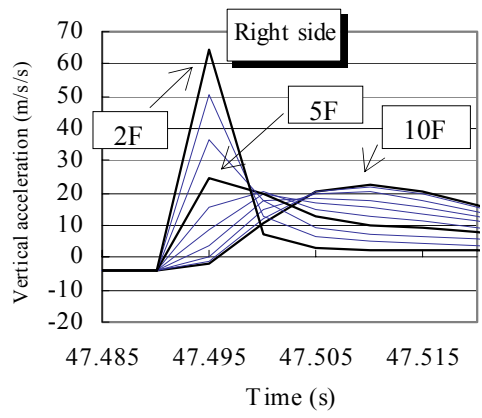

(b)

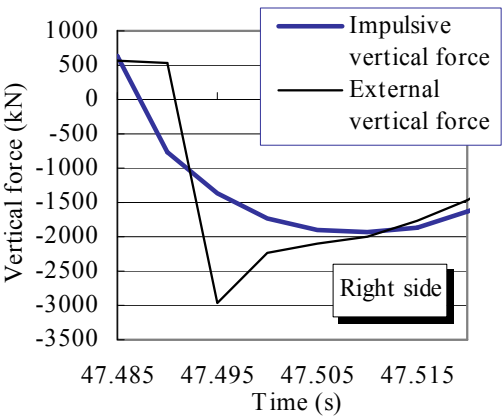

(d)

Figure 13: Time histories of vertical responses in 47.485 - 47.520s: (a) vertical response velocity, (b) vertical response acceleration, (c) external vertical force; and (d) comparison between impulsive vertical force and external vertical force at base. 
The external vertical force at the base calculated by Eq. (2) using the peak vertical acceleration values shown in Fig. 9 exceed the maximum of the impulsive vertical force shown in Fig. 12 largely. This result means that the vertical response accelerations on the frame may not reach their maximum simultaneously. In Fig. 13, time histories of vertical response velocity, acceleration, external vertical force by Eq. (2) and impulsive vertical force by Eq. (1) on the right side of the frame are shown focusing the time duration, 47.485-47.52s, when the peak impulsive vertical force is observed in Fig. 12.

Table 5: Viscous damping ratios for supplemental analysis.

\begin{tabular}{|c|c|c|}
\hline & $\mathrm{T}(\mathrm{s})$ & $\mathrm{h}(\%)$ \\
\hline 1st & 1.562 & 3.00 \\
\hline 2nd & 0.531 & 3.00 \\
\hline 6th & 0.106 & 12.03 \\
\hline
\end{tabular}

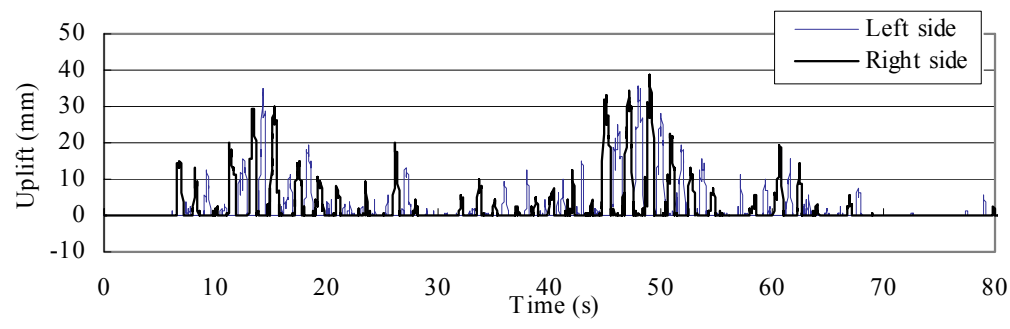

Figure 14: Time history of uplift displacement (supplemental analysis).

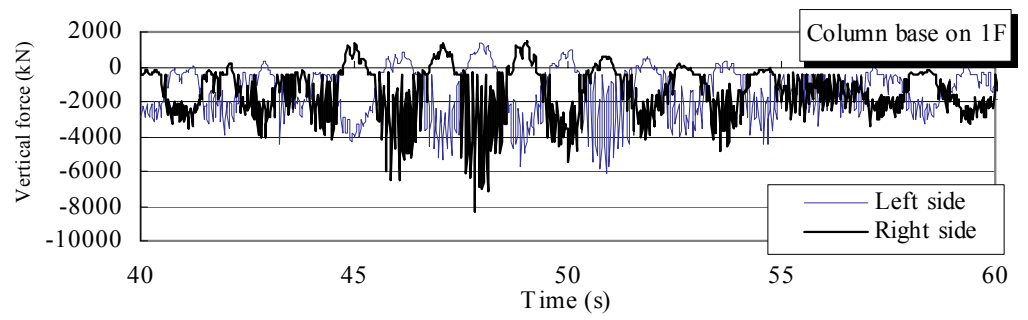

Figure 15: Time history of vertical force at base of BPY model (supplemental analysis).

Just before the column touches down, the vertical response velocity reaches its peak, that is about $0.40 \mathrm{~m} / \mathrm{s}$ on all floors as shown in Fig. 13(a). After that, the velocities diminish to zero. The velocity of the second floor damps most quickly. Fig. 13(b) and Fig. 13(c) show the phase difference between the responses of the lower floors and those of the higher floors. As shown in these figures, the vertical acceleration and external force are amplified largely only on the lower floors in the beginning. We can see that these amplified values do not directly 
correspond with the impulsive vertical force in Fig. 13(d). It is supposed that these are moderated by the effect of viscous damping in vertical.

To investigate the effect of the viscous damping in vertical, a supplemental analysis is carried out. The viscous damping type for the analysis is changed to the Rayleigh type. The critical damping ratios for the representative modes are shown in Table 5. Time histories of uplift and vertical force at the bases are shown in Fig. 14 and Fig. 15, respectively. We can see that the damping type affects on the peak uplift little, comparing Fig. 14 with Fig. 8. In contrast, when using the Rayleigh type viscous damping for the analysis, the impulsive vertical force obviously affects the response of the vertical force at the base. It means that we need further studies on the viscous damping in vertical including the soil viscous damping under the base to evaluate more precisely the influence of the impulsive forces on responses of the rocking structures.

\section{Conclusion}

The effect of the impulsive vertical force on earthquake responses of a real scale model frame that permitted uplift motion was investigated. When the uplifting columns touched down to their original position, the striking impulsive vertical forces were observed. However, they hardly affect the peak vertical forces at the bases, because these forces damped very quickly under the assumption of stiffness-proportional viscous damping.

The results of the supplemental analysis in which the Rayleigh type of the viscous damping was used shown that striking impulsive vertical force arose more distinctly on the vertical force at bases. It means the further study on the viscous damping in vertical including soil viscous damping under the base is required to evaluate more preciously the influence of the impulsive forces on the response of the rocking structures.

\section{Acknowledgement}

Part of this work is supported by the Ministry of Education, Culture, Sports, Science and Technology (MEXT) of Japan under Grant-in-Aid for Scientific Research, Project No. 18560520 and 16360284.

\section{References}

[1] Meek, J. W., Effects of foundation tipping on dynamic response. ASCE, Vol.101, No.ST7, pp. 1297-1311, 1975.7.

[2] Rutenberg, A., Jennings, P. C. \& Housner, G. W., The response of Veterans Hospital Building 41 in the San Fernando Earthquake. Earthquake Engineering and Structural Dynamics, 10(3), pp. 359-379, 1982.

[3] Hayashi, Y., Tamura, K., Mori, M. \& Takahashi, I., Simulation analyses of buildings damaged in the 1995 Kobe, Japan, Earthquake considering 
soil structure interaction. Earthquake Engineering and Structural Dynamics, 28(4), pp. 371-391, 1999.

[4] Clough, R. W. \& Huckelbridge, A. A. Preliminary experimental study of seismic uplift of a steel frame. Report No.UBC/EERC-77/22. EERC, University of California, Berkeley, CA, 1977.

[5] Iwashita, K., Kimura, H., Kasuga, Y. \& Suzuki, N. Shaking table test of a steel frame allowing uplift. Journal of Structural and Construction Engineering. AIJ 561, pp. 47-54, 2002. (In Japanese)

[6] Kasai, K., Kanda, M. \& Okuma, K. Real example for a passively controlled building with stepping column: analysis and full-scale damper experiment. Proceeding of Passive Control Symposium 2001. Structural Engineering Research Center, Tokyo Institute of Technology, pp. 235249, 2001. (In Japanese)

[7] Midorikawa, M., Azuhata, T., Ishihara, T., Matsuba, Y., Matsushima, Y. \&Wada, A., Earthquake response reduction of buildings by rocking structural systems., Proc. SPIE, Smart Structures and Materials 2002, pp. 265-272, 2002.

[8] Midorikawa, M., Azuhata, T., Ishihara, T. \& Wada, A., Shaking table tests on rocking structural systems installed yielding base plates in steel frames. Proc. of STESSA2003, pp. 449-454, 2003.6.

[9] Midorikawa, M., Azuhata, T., Ishihara \& Wada, A. Dynamic behavior of steel frames with yielding base plates in uplift motion for seismic response reduction, Journal of Structural and Construction Engineering. AIJ 572, pp. 97-104, 2003. (In Japanese)

[10] Midorikawa, M., Azuhata, T., Ishihara, T. \& Wada, A., Shaking Table Testson Seismic Response of Steel Braced Frames with Column Uplift. Earthquake Engineering and Structural Dynamics, 35(14), pp. 1767-1785, 2006.

[11] Ishihara, T., Midorikawa, M., Azuhata, T. \& Wada, A., Hysteresis characteristics of column base for rocking structural systems with base plate yielding, Journal of Construction Steel, vol. 11, pp. 51-56, 2003.11. (In Japanese)

[12] Ishihara, T., Midorikawa, M. \& Azuhata, T., Hysteresis Characteristics of Large-scale column Base for Rocking Structural Systems, Journal of Constructional Steel, 14, pp. 381-384, 2006. (In Japanese) 